\title{
El narciso democrático
}

\author{
The democratic Narcissus
}

\section{Dr. Carlos Ossa Swear}

(Santiago, 1962) El profesor Ossa es Magíster en Comunicación Social y Doctor en Estética y Teoría del Arte en la Universidad de Chile. Es autor de numerosos artículos internacionales indexados donde ha plasmado su visión crítica del cine y las artes. Asimismo es autor de varios libros, entre los cuales destacan: "El ojo mecánico. El cine político y comunidad en América Latina" (2013, FCE); "Escrituras del malester. El Chile del Bicentenario" (2011); "La semejanza perdida" (2009). En la actualidad el profesor Ossa se desempeña como investigador en el ICEI, Universidad de Chile.

\section{Resumen}

Las transformaciones sufridas por el sistema comunicacional en Chile establecen la desaparición de lo público como un componente decisivo. A causa de ello la concentración estaría afectando la pluralidad y el significado de lo social. Sin embargo, se puede sugerir que hoy se produce una dimensión de lo público asociado a nuevas configuraciones y representaciones que dependen de una gubernamentalidad de lo mediático. Ella instala su trabajo en el campo de la conducta y de las emociones y ofrece una diversidad narrativa a las identidades que ponen en discusión el carácter de las políticas públicas.

Palabras clave: Transición, estado, comunicació, gubernamentalidad, felicidad.

\section{abstract}

The transformations undergone by the communication system in Chile establish the disappearance of the public as a decisive component. Because of this concentration would be affecting the plurality and meaning of the social. However, it can be suggested that today there is a dimension of the public associated with new configurations and representations that depend on a governmentality of the media. She installs her work in the field of behavior and emotions and offers a narrative diversity to the identities that challenge the character of public policies.

Key words: Transition, state, communication, governmentality, happiness. 


\section{Introducción}

A contrapelo de la vieja -pero siempre reiterada dicotomía entre lo privado y lo público- podríamos decir que el Estado chileno, ha creado el mercado de las comunicaciones como una política cultural. Renunció a la función garantista y se concentró en la operación managerencial. Así, introdujo lo subsidiario en los problemas sociales. De esta manera una cierta obsolescencia epistémica atraviesa la discusión sobre las prácticas discursivas, los roles profesionales, la libertad de expresión o las redes informáticas. Los cambios ocurridos en la relación entre economía, comunicación y cultura dan cuenta de una situación específica: la lengua a compartir entre sociedad e instituciones está rota y sólo a través de efectos lingüístico-cognitivos se consigue una ilusoria unidad. Pero no estamos en un mundo descentrado, abierto a la especulación simbólica con múltiples escenas, al revés esta diversidad sólo expresa la estética inmóvil del capital.

En una perspectiva histórica, al no producirse una ruptura institucional entre la dictadura y la transición, los marcos del lenguaje político y sus ceremonias; las formas de la cultura visual y sus clichés; los objetos de lo sensible y su valoración sirvieron a un enjambre de transferencia de códigos, préstamos e imaginarios que tenían en común desactivar lo social y sus movilizaciones. La transición democrática por tanto hizo de la comunicación y de los medios masivos, un espacio de repartición de lo sensible (Ranciere, 2009) al ofrecer nuevos modos de sentir y trabajar que no necesitaban los soportes de la república clásica para existir. Las visiones instrumentales continuaron, pero se negaron a suscribir el ritmo de una mimesis informativa y más bien se orientaron a crear distintas opciones de uso y abuso de la vida cotidiana logrando instalar un contrato mediático con ella (Verón, 2001).

La estructura de cierre narrativo que en los últimos 40 años definen las rutinas de los medios es paradojal, pues mantener el límite significa siempre ampliarlo, colocando en lo diario amenazas fragmentarias y escándalos inalcanzables. Es la manera de reducir el síndrome social y suspenderlo -nunca destruirlo- por un horizonte de crisis continua. Hay un desplazamiento interesante, los medios pasan de vigilar la intimidad a fiscalizar la gubernamentalidad. Es una breve tregua para ajustar el modelo a los índices productivos que requieren una psicología del desengaño, en conexión, con la identidad individual dominante. Es decir, contribuir a la desilusión política para seguir encerrados en los ejes del trabajo y recibir la confirmación existencial de lo útil del tiempo dedicado a sí mismos. A ello cabe agregar la urgencia por restituir un verismo antropológico que dote a los medios de cierta hegemonía al interior de un espacio comunicacional estallado por las redes, que modifican los criterios de información y exaltan hasta lo esquizofrénico la opinión como sinónimo de verdad. Por otra parte, la industria medial descubre la 
potencia lúdica de estetizar la actualidad y hacer de ella el texto vacío que repite incansablemente dos ideas: mantener el orden y corregir su imperfección.

En un plano general las comunicaciones se han convertido en un repositorio de estilos de vida de clase media, en una diagramación de las identidades periféricas; en un panóptico de la sensibilidad popular ${ }^{1} \mathrm{y}$ en una óptica de las corporaciones. La heterogeneidad del proceso explica, en parte, la tendencia a uniformar el material para tener un control directo sobre los territorios de la representación. De acuerdo a Felipe Blanco:

La transición significó en las industrias televisivas la homogenización de las franjas, la estandarización interna de los noticieros, la repetición de los focos programáticos y como resultado de esos procesos, una indiferenciación que se hizo más notoria en la medida que dos factores de contenido inundaron las agendas mediales: la farándula como operación y los realities (2014:30).

Frente a este escenario ¿qué sería lo público? Parece difícil imaginar la pertinencia de una racionalidad comunicativa o la utilidad de una pluralidad neofuncionalista y sin embargo, ambas construyen una no-

1 Lo privado con sus múltiples maneras de concurrir y agotar lo inmediato, la variedad de noticias que sustentan su presencia y la continua creación de personajes e historias ha copado la atención pública, se ha mediatizado, liberándose de ese silencio riguroso y declinante con el cual fue aprisionado por una economía del rendimiento. Pero esto se debe también a que la televisión construye un gobierno tecnológico para el discurso personal -sabe la importancia política que tiene- y el impacto de su visibilidad, por ello las breves aventuras, los amores fatuos, las amistades verdaderas o los episodios maravillosos no hablan de ciudadanías pueriles desgastándose en la información y la publicidad, sino de ceremonias mediáticas donde los cuerpos brillan y olvidan la expropiación a la que están sometidos. ción sumisa a fines institucionales. Por lo mismo, hoy se produce lo público de una manera intensa y extensa generando un contenido normativo que define lugares y posiciones. A pesar de la propiedad privada de los medios éstos hablan como una razón de Estado. La criminalización de las protestas sociales es el mejor ejemplo del neopopulismo que los medios han producido. Fueron esas protestas las que dieron oportunidad de redefinir la agenda e instalar el "giro asistencial" donde los significantes de la noticia sirvieron primero de policías simbólicos y luego de pacificadores sociales: una especie de tercerización del orden donde los medios se convierten en agencias estatales desreguladas y en predicadores de su excepción.

La discusión sobre la información, su propiedad y acceso ha sido el núcleo narrativo de diversos proyectos que intentan definir las condiciones de la industria mediática y minimizar los derechos de los consumidores. La insistencia en democratizar los formatos, los financiamientos y las autorías intentan reponer lazos históricos de protagonismo y audiencia. Pero ¿cómo definir hoy a las ciudadanías? En general los Estados trabajan con referentes organizados y nula vez interpelan a los individuos particulares ¿qué tipos de sujetos constituyen las ciudadanías y por qué ellas serían las justas destinatarias de la apertura medial? O bien ¿qué nomenclaturas imponen las políticas sociales para determinar la visibilidad y cómo ellas se instalan en las comunicaciones a modo de referente?

La modernización neoconservadora, consolidada por los regímenes democráticos, diseñó una esfera tecnificada de participación y desarrollo (Arfuch, 2005). Bajo el amparo de los poderes fácticos no sólo se restringieron los cambios sociales a agendas de negociación, además se propuso establecer 
FACSO-UCE

un tipo de subjetividad disciplinada. En las últimas dos décadas la voz concentracionaria de una elite asfixiante ha construido una "esfera escópica" cuya función es naturalizar la desigualdad al modo de una mitopoesis obsesiva con el relato de la ganancia. Analizar este fenómeno, cuyas fronteras imprecisas contribuyen a reiterar esquemas y modelizaciones, implica preguntarse por las ideologías que establecen el debate. Habría una prosa de la participación de la cual serían portadores los "miembros" de la sociedad; una poética de la invisibilidad generada por los medios y los intereses económico-políticos y una dramaturgia de la reforma propuesta por el Estado en su intento de mantener y externalizar los vínculos sociales. El funcionamiento de cada entidad -en su autonomía y dependenciaindica el itinerario y las tácticas que han conformado la discusión sobre las comunicaciones a nivel profesional y académico. Pero al modo de un sedimento imborrable queda en la textura de la mediatización un ícono: el "narciso democrático", la forma tautológica de usar la palabra y la imagen para establecer la primacía de la familia política como empresario y artista: audacia y genialidad. ¿Qué tipo de participación se puede tener en los tejidos de una cultura mediática corporativizada? ¿Estamos en presencia de una iconoclastía neoliberal? ¿Qué políticas públicas de comunicación se pueden pensar sin discutir la naturaleza biopolítica de la democracia chilena? Las comunicaciones generan más que rentabilidad: se instalan en el flujo de la existencia colectiva y expropian -todos los días- cuotas de energía psicológica y física que sirven de movimiento a un poder antropófago que administra máquinas de producción y deseo:

"Tanto más hoy, cuando el cuerpo humano es cada vez más desafiado, in- cluso literalmente atravesado, por la técnica. La política penetra directamente la vida, pero entretanto la vida se ha vuelto algo distinto de sí misma. Y entonces, si no existe una vida natural que no sea, a la vez, también técnica [...] ¿cómo hipotetizar una relación exclusiva entre vida y política?" (Esposito, 2006:25).

Las emociones vendrían a ser ese gobierno neutro que tendría la función de normalizar la convivencia, reorganizar la pragmática social, generar la cohesión nacionalista del consumo, reprogramar la dimensión socio-espacial de la ciudad y sus jergas. En suma, una parte significativa de la operación pública medial está centrada en la elaboración de una gramática de la felicidad que a diferencia -de su versión ilustrada- no atiende sólo los aspectos redistributivos y materiales (incluso los omite) a favor de la satisfacción detallada de la conducta. Existe un conjunto de subsidios, vouchers y bonos subjetivos que las comunicaciones otorgan, a cambio de cuerpos consumiendo y de emociones participando de la cadena suplementaria de prestaciones informativas, estéticas, culturales, económicas y políticas. Es una relación de reciprocidad asimétrica, donde se ponen en conflicto distintos objetivos y procesos, pues no existe una audiencia única y tampoco diálogos monocordes, pero hay una desigual proporción entre quienes dirigen los sistemas y quienes los padecen. "De este modo, entonces, considerada una de las escasas emociones que comporta un carácter positivo, la felicidad se conformará en un reconocible objeto de gestión gubernamental" (Pincheira, 2012:119).

¿Cuáles serían las narrativas de la diversidad que la comunicación ofrecería como distintas a las creadas por el mercado y las llamadas industrias creativas? La sociedad chilena contemporánea es presen- 
tada en diversos formatos como un órgano regular de producción e intercambio que suele ser afectado por la irrupción de lo caótico o lo catastrófico. A fin de mediar ante la irregularidad de los hechos se hace necesario ofrecer una transición discursiva que explique la anomalía y luego la normalice, de ahí, entre otras cosas el papel de los expertos y los especialistas que indican las orientaciones fundamentales y los medios de realizarlas. Estas figuras son traductoras de normalidad y tienen la capacidad de dotar de sentido representacional a sus afirmaciones. Así, las marcas de lo perverso son intervenidas y modificadas, dando pie a promesas de mayor tolerancia y placer, por ejemplo, comienzan a volverse aceptables la diversidad sexual, el patrimonio etnográfico, la crítica a las instituciones y la multiplicidad ciudadana. "Armada sobre la certeza de su repetición, la cotidianidad es ante todo el tejido de tiempos y espacios que organizan para los practicantes los innumerables rituales que garantizan la existencia del orden construido" (Reguillo, 2000: 77).

\section{Economía del lenguaje}

Esta fusión de libertad de mercado con democracia está en el corazón de la filosofía y politicas de comunicación de la Concertación.

Rosalind Bresnahan

Las comunicaciones han jugado un papel decisivo en la reconversión productiva del mundo popular, han orientado el vocabulario de la fuerza de trabajo levantando consignas de prosperidad y éxito personal. En este sentido, logran que los "civiles" identifiquen demanda política y deseo financiero como iguales, pero susceptibles sólo de alcanzarse al interior de los acuerdos establecidos por los centros partidarios. $\mathrm{El}$ horizonte institucional es el límite del discurso y por lo mismo la voz monótona de artistas, funcionarios, comunicadores, deportistas, académicos reitera ese fondo irreversible de lo obvio y lo obtuso. Las políticas públicas, entonces, se transforman en construcciones tácticas de ciudadanías que puedan ser operativas en distintos momentos históricos. Movilizar a las mismas como garantes del consenso, a través de un verosímil didáctico que resuelva con frases cortas y técnicas publicitarias, la tensión entre desigualdad y modernización. Esta dimensión de la planificación social es discontinua, se avanza y retrocede, pero hace funcionar un dispositivo complejo de enunciación que a lo largo de los años, ha establecido una serie de "criterios de realidad" y "pragmatismos":

a. la institucionalización del pacto: narrar la proeza mesiánica de una política que superó el subdesarrollo, la polarización, la pobreza y convirtió la desmesura geográfica en economía de exportación

b. la consolidación de la tregua: el triunfo jurídico que despolitiza la violencia al transformarla en archivo y tribunal que compensa la catástrofe con indemnizaciones e informes periodísticos

c. la reforma ciudadana: la escenificación de la demanda social mediante su atención terapéutica, a través de paneles de expertos y mesas de diálogo comunicacional, destinadas a corregir las anomalías

d. el giro emotivo político: la apelación al gobierno de las emociones para impedir el desborde desilusionante de movimientos sociales y consumidores ante la disonancia cognitiva que genera la desigualdad

El paso de lo dictatorial a lo democrático se explicaría por la inserción de 
Chile en esa corriente mundial de la modernización que requiere un nuevo ethos comunicacional para legitimar el triunfo de la voluntad soberana. Un tiempo donde la solidaridad de la globalización se expresa aceptando las economías menores en el gran teatro del capital financiero y permitiendo que éstas se beneficien a través de los costos decrecientes, la precarización, el outsourcing, la desregulación, la especulación inmobiliaria o el fondo crediticio. $\mathrm{La}$ necesidad de dar una coherencia teleológica a los fundamentos de esta forma del poder implica redefinir las políticas públicas de comunicación, no eliminarlas. Se trata de modificar la visión antropológica del rendimiento pasivo por la innovación de la identidad, ahora, no sujeta a ningún canon e ideología, sino al dogma escatológico de cada "individuo una empresa".

De acuerdo a lo descrito, nos gustaría afirmar que las políticas públicas de comunicación no están pensadas, en términos ilustrados de representación, reconocimiento y derechos, sino de políticas culturales dedicadas a la gestación de una subjetividad disciplinada que acepta el orden como una gramática de la felicidad. El Estado abandona las "ineficaces" consecuencias modernas del control medial (aparato y cultura oficial), pero incrementa las "adecuadas" consecuencias de la gubernamentalidad. En suma, las comunicaciones en Chile han sido partícipes estratégicas de la creación de una población económica que para sostener el modelo debe ser tratada como si fuera una comunidad política. En los noventa, un principio rector, era describir a la sociedad chilena como moderna y ya liberada de atrasos culturales y retóricas mágico-folclóricas, la secularización, el consumo y la democracia eran las novedades mediáticas indiscutibles. Ellas preparaban a los sujetos para dar el salto desde una vida atada a la directriz estatal hacia la autorrealización existencial y la emancipación económica. Pero, la determinación de tecnificar el orden para suprimir el conflicto y hacer de ello la estrategia del lenguaje implica que:

"El privilegio de la negociación de las élites, como vía hacia la paz social, consustancial a los modelos de consenso, conlleva además otra dificultad la de marginalizar la expresión política de los conflictos sociales y económicos. Esta marginalización conduce a una tendencia excesiva a la autonomización de la esfera política frente a otros ámbitos de la vida social percibidos como fuentes de división, de pasiones y de violencia, es decir, en suma de irracionalidad" (Ruiz, 2008:12).

La autonomía personal idealizada por la publicidad, vigilada por el poder y confesada por la comunicación no confirma el fracaso de la comunidad política, sino la desventaja narrativa en la que vive ante el universo concentracionario de la acumulación. La importancia que adquiere el tiempo de la intimidad como modelo de convivencia es proporcional a la ruptura del contrato vinculado a derechos y resistencia. Una communitas débil mantiene la unión de los individuos en el consumo y desconfía de las ideologías de la participación social. Los idiomas tecnológicos, los optimismos mercantiles, las transacciones bursátiles condensan el discurso de la victoria del capital. Sin embargo, no ha desaparecido la representación, como podría creerse, ha cambiado de destrezas y vocablos, postula la combinación y el quiebre como retóricas de ensamblaje para dar a las narrativas mediáticas la oportunidad de corte y velocidad. Se puede hablar de historias cortas, es decir, de un tiempo donde lo público queda obturado de cualquier vínculo de historicidad, a favor de lo repentino y adecuado. 


\section{Cierre}

Si los conceptos de espacio público y ciudadanías políticas, parecen no resistir las definiciones de desconstrucción y desterritorialización, cabría pensar en la urgencia por trabajar otras epistemes y adecuar nuestro pensamiento a un tipo de entropía que caracteriza al capitalismo contemporáneo. El centro de la riqueza, hoy en día, está en la producción inmaterial y el lenguaje se transforma en el motivo de la codicia. Poseerlo, adecuarlo y reinventarlo es parte de los fenómenos glamorosos de esta época y que hacen de las redes sociales la zona privilegiada de inversión y vigilancia. La comunicación está relatando otro concepto de lo público que no guarda simpatía con las reivindicaciones ético-políticas de ciertos organismos y movimientos. Es un mundo fascinante de objetos y oportunidades destinado a la singularidad, al emprendimiento y la desconfianza en lo colectivo, es un concepto sin cuerpos, sin pueblo, sin memoria y sin dolor. Es la imagen más elocuente del abismo. 


\section{Textos y Contextos}

FACSO-UCE

\section{BIBLIOGRAFIA}

Arfuch, L., (2005) (Comp.) Identidades, sujetos y subjetividades. Buenos Aires: Prometeo libros.

Avelar, I., (2000) Alegorías de la derrota. La ficción postdictatorial y el trabajo del duelo. Chile: Editorial Cuarto Propio.

Blanco, F., (2014) "La irrupción de la realidad en la ficción televisiva" en Barril, C., Corro, P., Santa Cruz, J., Audiovisual y politica en Chile. Santiago, Editorial Lom.

Castells, Manuel, (2006), Globalización, desarrollo y democracia: Chile en el contexto mundial. Santiago: Fondo de Cultura Económica.

Delamaza, G., (2012) "Agendas de política social y construcción democrática en la transición chilena" en Revista de Gestión Pública (V. 1 N $^{\circ}$ 2) 311-386. http://www.revistadegestionpublica.cl/Vol I No $2 /$ Delamaza.pdf

Esposito, R., (2006) Bios. Biopolitica y Filosofia. Buenos Aires: Amorrurtu/Editores.

Imbert, G., (2003) El zoo visual. De la televisión espectacular a la televisión especular. Editorial Gedisa, España.

Lechner, N., (2006) Obras Escogidas. Tomo I. Editorial Lom. Chile.

Pincheira, I., (2012) "De bonos, cheques y vouchers: acerca de la gestión gubernamental de la felicidad en el neoliberalismo chileno" en: Tijoux, E., Scribano, A., Archivos de frontera. El gobierno de las emociones en Argentina y Chile del presente. Santiago de Chile. Ediciones Escaparate.

PNUD (2002) Desarrollo Humano en Chile. Nosotros los chilenos: un desafio cultural. Santiago: Programa de las Naciones Unidas para el Desarrollo.

Ranciére, J., (2009) El reparto de lo sensible. Estética y Política. Santiago: Editorial Arcis-Lom.

Reguillo, R., (2000) "La clandestina centralidad de la vida cotidiana". En Lindón, Alicia (Coord) (2000) La vida cotidiana y su espacio-temporalidad. México: Co-edición Universidad Nacional Autónoma de México, el Colegio Mexiquense y Anthropos Editorial.

Ruiz, C., (2008) "La democracia en la transición chilena. Posibilidades y límites".

https://www.u-cursos.cl/filosofia/2008/0/SGFIL/3/material.../bajar?id...

Salazar, M., Valderrama, M., (comp.) (2000) Dialectos en transición. Politica y subjetividad en el Chile actual. Santiago: Ediciones Lom-Arcis.

Sibilia, Paula (2009) La intimidad como espectáculo. Buenos Aires: Fondo de Cultura Económica.

Verón Eliseo (2001) El cuerpo de las imágenes. Enciclopedia Latinoamericana de Sociocultura y Comunicación. Bogotá: Editorial Norma. 